MANUSCRIPT CURRENTLY UNDER REVIEW. PLEASE DO NOT CITE OR CIRCULATE WITHOUT PERMISSION.

\title{
Varying versions of moral relativism: The philosophy and psychology of normative relativism
}

\author{
Katinka J P Quintelier ${ }^{\mathrm{a}, \mathrm{b},{ }^{*}}$ and Daniel M.T. Fessler ${ }^{\mathrm{b}}$ \\ ${ }^{a}$ Ghent University, Department of Philosophy and Moral Sciences and Research Unit \\ 'The Moral Brain', Blandijnberg 2, B-9000 Ghent, Belgium. \\ ${ }^{\mathrm{b}}$ University of California, Los Angeles, Department of Anthropology and Center for \\ Behavior, Evolution, \& Culture, Los Angeles, 375 Portola Plaza, 341 Haines Hall, Los \\ Angeles, CA 90095-1553, USA \\ *Corresponding author: katinka.quintelier@UGent.be
}

\begin{abstract}
Among naturalist philosophers, both defenders and opponents of moral relativism argue that prescriptive moral theories (or normative theories) should be constrained by empirical findings about human psychology. Empiricists have asked if people are or can be moral relativists, and what effect being a moral relativist can have on an individual's moral functioning. This research is underutilized in philosophers' normative theories of relativism; at the same time, the empirical work, while useful, is conceptually disjointed. Our goal is to integrate philosophical and empirical work on constraints on normative relativism. First, we present a working definition of moral relativism. Second, we outline naturalist versions of normative relativism, and third, we highlight the empirical constraints in this reasoning. Fourth, we discuss recent studies in moral psychology that are relevant for the philosophy of moral relativism. We assess here what conclusions for moral relativism can and cannot be drawn from experimental studies. Finally, we suggest how moral philosophers and moral psychologists can collaborate on the topic of moral relativism in the future.
\end{abstract}

\section{Keywords}

moral relativism; moral psychology; experimental ethics; normative ethics; tolerance

\section{Moral Relativism and its opposites}

The goal of this paper is to integrate recent naturalist philosophical and moral psychological work on moral relativism. Philosophers draw distinctions between cultural and individual relativism, and between extreme and moderate moral relativism, and ask what moral prescriptions are in accordance with human psychology. However, moral psychologists generally do not employ these distinctions, making it difficult to examine the extent to which their research findings can or cannot be compared to various philosophical positions. We aim to bridge this disciplinary divide and integrate this conceptual landscape in contemporary and future research. Where appropriate, we will 
make explicit and defend our philosophical commitments, and clarify the concepts we use. We start by introducing a working definition of moral relativism.

The term 'moral relativism' is associated with a variety of very different concepts, some of which function mainly to oppose the view. Schematically, we intend to use the term as follows: Moral relativism consists of three components. First, it holds that descriptive, prescriptive, or meta-ethical aspects of prescriptive terms such as 'right,' 'wrong,' 'ought,' etc. (e.g., their use, legitimacy, or meaning) are relative to a moral view. Second, moral relativism holds that there is variation in these moral views, and, third, this variation cannot be entirely eliminated, either practically or by following certain epistemological rules.

This is quite abstract; in order to clarify this we will first give a stylized example of moral relativism and then contrast moral relativism with other ethical views that are sometimes used as its opposite. Since we are interested in the empirical constraints of normative, or prescriptive moral relativism, we give a normative example. Assume that Claudia, a prochoice activist, says abortion is permissible and is having an abortion; meanwhile Susan, a pro-life activist, says abortion is wrong and she continues her pregnancy. A normative relativist may hold that Claudia is permitted to have an abortion because it is in accordance with her values while at the same time it would be wrong for Susan to have an abortion because abortion is not in accordance with Susan's values; the moral relativist may also hold that his own moral standards are not important in judging Claudia or Susan. The normative relativist can, moreover, hold that pro-life and pro-choice values are both equally legitimate.

As to normative relativism's opposites, we turn to the three components that we outlined. The first component relates legitimacy to moral views, meaning that what is right or wrong depends at least partially on a subject's or culture's moral views and not entirely on anything that exists independent of people's minds. This makes moral relativism markedly different than moral objectivism, the latter here holding that what is right or wrong is substantially mind-independent. With this meaning of moral objectivism we stay very close to its use by scholars whose work we will discuss later in Sections 3 and 4

(e.g., Ruse 1986; Nichols and Folds-Bennett 2003; Goodwin and Darley 2008). The second aspect in our scheme concerns scope, where relativism is distinct from universalism. Moral universalism holds that acts are right or wrong for everyone. Universalism does not entail any metaphysical claim: objectivism and universalism may be orthogonal concepts, though objectivism usually entails universalism. These concepts will be of interest in Section 4, when we evaluate normative theories' empirical assumptions. But first we turn to distinctions and theories within normative relativism.

\section{Distinctions and theories within normative relativism}

First, an important initial distinction is between extreme and moderate relativism (Moser and Carson 2001; cf. Sinnott-Armstrong, 2009). Extreme normative relativism holds that all moral actions are relatively right or wrong, or that every action can be required or ought to be tolerated or respected. Those who criticize moral relativism often equate 
relativism with extreme normative relativism. According to Levy (2002: 25), for example, its opponents fear that "If relativism is true, then there are no absolute moral standards in the name of which we can denounce the Nazi holocaust, the slave trade or the Spanish Inquisition...If relativism is true, then anything goes." According to Brandt (1967/2001:28), the following extremely relativistic view is popular: "if someone thinks it is right (wrong) to do A, then it is right (wrong) for him to do A," a view that amounts to subjectivism. However, contemporary moral philosophers hardly ever defend extreme normative relativism. ${ }^{1}$ Instead, their view is best described as moderate normative relativism, which holds that some but not all moral actions are relatively right or wrong, and other moral actions are universally right or wrong. Wong $(1984 ; 2006)$ and Levy (2002), for example, hold that we can find many different existing moral views, but only a subset of these are legitimate.

Second, there is a continuum with cultural relativism at one end and individual relativism at the other end. Individual relativism holds that an action is right or wrong depending on the moral view of the individual. In contrast, cultural relativists hold that whether an action is right or wrong depends on the moral viewpoint of the individual's culture. In works on moral relativism, the distinction between individuals and their cultural context is often implicit (e.g.Beebe, 2010).

A common prescriptive view discussed under the rubric of moral relativism is tolerance. A prescription to tolerate means that you should not interfere with actions that you (or your culture) consider wrong. Again, moderate tolerance means that not all actions ought to be tolerated; only a subset of the actions one deems wrong ought to be tolerated (Wong 2006). Often tolerance is only required of moral relativists. The idea of tolerance is criticized for being psychologically impossible (Section 3); accordingly, some empirical studies touch upon the topic of tolerance (Section 4).

Irrespective of empirical findings, Wong (2006) rejects tolerance. Instead, he recommends that if one considers an act to be wrong, one should accommodate, meaning that one should attempt to understand the other's viewpoint. For example, stated simplistically, the Western world prioritizes autonomy over community, while the Eastern world prioritizes community over autonomy. Individuals from both types of cultures can nevertheless understand that autonomy and community are valuable. When confronted with another morality, one thus has to put oneself in the other's shoes. Wong's theory is relativistic because it centralizes the notion of ambivalence. Ambivalence happens when one comes to understand the other's point of view, and thereafter holds two values in mind. These values thus prescribe irreconcilable actions for one and the same actor. If community-values dictate that one must take care for one's family, while autonomy-values dictate that one must pursue one's own interests, one experiences ambivalence. This experience is similar to that of a moral dilemma : "even if we are firm in taking a side, we can understand that something of moral value is lost when we act on that side, and the loss is of such a nature that we cannot simply dismiss it as a regrettable though justifiable result of the right decision" (Wong 2006: 21).

\footnotetext{
${ }^{1}$ This is different for meta-ethical relativism: meta-ethical relativism is most often presented or defended in its extreme form, namely that all moral statements are relatively right or wrong if meta-ethical relativism is correct. For a discussion of this view, see Sinnott-Armstrong 2009.
} 
Wong's view resembles notions of respect. For Levy (2002: 62-66), respect demands that one tries to understand the value of certain other ways of life in order to either affirm them as worthwhile or reject them as illegitimate. For Heyd (1996), respect is the value of understanding individuals in order to evaluate them independently of their acts. Respect here entails that one does not immediately judge the person because of his or her actions.

\section{The relevance of empirical data for philosophical theories}

When arguing for or against the theories sketched above, naturalist philosophers introduce both normative and empirical assumptions. Below we outline their major arguments with the aim of evaluating their empirical assumptions in Section 4.

\subsection{Arguments for normative relativism}

A popular line of argument in defense of normative relativism, procedural argument, depends on the existence of fundamental disagreement. This is disagreement that cannot be resolved by a specified procedure. An example of such a procedure is given by Brandt when he says that, to assert that moral disagreements are non-fundamental is to presume that "all ethical diversity ${ }^{2}$ can be removed, in principle, by the advance of science, leading to agreement about the properties of the things being appraised," (1967/2001: 2526). If moral disagreement cannot be removed by the advance of science, then Brandt speaks about fundamental moral disagreement. Other such procedures have been proposed (Levy 2002: 77; Wong 1984: chapter 12; Wong 2006; Doris and Plakias 2008). In general, a procedural argument holds that when one cannot convince others with 'reasonable' arguments, this is, arguments that comply with the accepted epistemology, one has no right to impose one's view on others. We can clarify this reasoning with the following example: A pro-life activist might want to convince a hearer that abortion is wrong. However, both might think that only rational arguments are acceptable. If the activist has exhausted all her rational arguments without convincing her conversational partner, then she is not justified in prohibiting or interfering with the hearer's abortion, even though she is certain that abortion is wrong. Granted, the activist might consider attempting to influence the other with more manipulative techniques, such as repulsive and saddening images of dead fetuses. While affective reactions might induce one to disapprove of abortion, such images, and the affects they induce, do not constitute rational arguments. The pro-life activist is therefore not warranted to use these arguments, or to interfere with abortion.

Other naturalist arguments in defense of normative relativism follow the same strategy of starting from empirical assumptions about moral diversity and introducing normative

\footnotetext{
${ }^{2}$ Ethical diversity is here the same as moral diversity. All moral disagreement is an instance of moral diversity but not all moral diversity is an instance of moral disagreement.
} 
assumptions. However, since we will mainly evaluate empirical arguments against specific theories of normative relativism, we will now discuss the latter.

\subsection{Arguments against normative relativism}

Other philosophers have objected that we cannot impose relativist norms on people because it would not fit with our species' moral psychology. First of all, in order to tolerate other points of view, one has to be capable of entertaining the idea that different requirements hold for different people. A first critique argues that this way of thinking about morality is not possible. This is the problem of feasibility. Ruse (1986) argues that we evolved to think of morality as objectively true in the service of motivating us to act upon our values. As a consequence, people are innately objectivist about morality. Another consequence is that, should one manage to think of a judgment as relative, then one necessarily would no longer think of it as a moral judgment. This leads us to ask if people are indeed inclined to be moral objectivists. We will examine empirical results that speak to the question of the feasibility of normative relativism in Section 4.

Flanagan (1991), who is equally committed to a notion of feasibility (Flanagan 1991: 32), stresses that we have to make a distinction between the realizability of relativism for everyone and its realizability for particular individuals (Flanagan 1991: 48). In this view, it might be psychologically plausible to impose a relativist morality on some people but not on everyone. Interpreted like this, the problem of feasibility simply leads us to ask whether at least some people are moral relativists. In Section 4 we will therefore examine empirical findings on individual differences in moral relativism.

Wong (2006) presents a still more nuanced take on psychological realism. He claims that we should not ask whether something is feasible; instead, for epistemological reasons, the criterion should be that it is not impossible. Even more, moralities that wrongly reject possible requirements should be ruled out as legitimate moralities: "Interestingly, however, seeing that certain possibilities are real enough (if not realistic) also works as a constraint on adequate moralities. Those moralities that in some way depend for their acceptance on denying the reality of certain possibilities must also be ruled out as inadequate," (Wong 2006: 176). This more nuanced interpretation of the problem of feasibility leads us to ask if we can reasonably say that it is impossible for human beings to think of morality as relative, no matter what the developmental conditions. Again, empirical research bears on this question (Section 4).

A second critique holds that, if we do think of morality as relative, then we will come to rely less upon moral values. This is the problem of confidence. Moral relativism would lead us to weaken our adherence to moral principles, thereby being less motivated to act or judge in accordance with them. This problem of confidence is foregrounded by Ruse (1986) when he says that "we think [morality is] binding upon us because we think it has an objective status," (his emphasis). As we will see in Section 4, studies have compared the (reported) moral behavior of relativists and non-relativists. 
A third criticism specifically holds for tolerance. Judging an act to be wrong allegedly implies that we are motivated to stop the action. An appeal to tolerate what we condemn is unstable because it goes against the drive to interfere with what we condemn. This is the paradox of toleration. Fletcher (1996) gives a clear account of the paradox of toleration: "tolerance presupposes a complexity of two sentiments: the first, an impulse to intervene and regulate the lives of others, and the second, an imperative - either logical or moral - to restrain that impulse," (Fletcher 1996:158). For this reason, tolerance will never hold for long.

Wong (2006) equally rejects tolerance; he therefore suggests that ambivalence and the process of accommodation will introduce new values and open up new morally permissible possibilities - without devaluing our previous commitments or urging us to intervene in previously condemned behavior. Levy's (2002) and Heyd's (1996) notions of respect are inspired by the same rejection of tolerance. However, criticisms of tolerance beg the question of whether disapproving an act is in fact psychologically linked to an irresistible impulse to intervene. This is, after all, an empirical question.

\section{Empirical studies on moral relativism}

\subsection{Feasability}

\subsubsection{Defining moral relativism away}

Are individuals inclined to think of morality as non-relative, as Ruse (1986) proclaimed? At first sight research into the development of morality indeed hints that our moral psychology is at odds with relativism. Piaget argues that, by the age of seven, children are moral realists, meaning that they regard values as independent of the mind and imposing themselves, regardless of the circumstances (Piaget 1932: 106). However, after the age of ten, rules in general are conceptualized as autonomous, being thought of as man-made and as legitimated by consensus or conformity. Different rules can be fair if everybody agrees with them or follows them (Piaget 1932: 57). Hence, in this view, children start off as moral non-relativists but develop in the direction of relativity (Piaget 1932: 316). However, Kohlberg added four more stages after the two moral stages proposed by Piaget. In Kohlberg's scheme, the final stage of moral development is characterized by the form of norms: moral rules are right whenever they are universalizable. Stages three to five are characterized by the content of general moral principles - interpersonal relations, social order, and rights, respectively. Accordingly, individuals who have reached stages three to five think that all moral rules are guided by those specific universal principles, while individuals who have reached stage six hold that moral rules are right whenever they are universalizable.

A closer look at this research adds nuance to the above conclusions. Kohlberg's conception of morality was biased towards non-relativism: he defined the moral domain by referring to Kant's formal principle of universalizability. This necessarily limits the 
scope of empirical investigation. If the researcher does not conceptualize a certain rule as universalizable, it will not be studied as a moral rule, even if subjects would categorize the rule as moral, if asked. Granted, one needs a prior conception of morality in order to know what to investigate. However, this conception could be minimal and broader at the start, allowing the data to guide the investigation by, for example, asking participants if the rule has anything to do with morality as they conceptualize it. Kohlberg-inspired methods are biased towards finding people to be moral non-relativists. For example, consider instruments such as Rest's Defining Issues Test (Rest 1979). It is not surprising that moral reasoning scores, and hence moral universalism, increase with age (Rest 1983) and college attendance (Rest 1988), given that only universalist thinking is seen as moral thinking by the investigators.

The above problem shows up to an even larger extent in domain theory and, more specifically, research concerning the postulated moral-conventional distinction. Theorists in this tradition (e.g., Turiel 1983; Turiel et al. 1987; Smetana 2006; Schweder 1990) hold that people make a distinction between 'morality' and 'convention.' In early work, Turiel (1983: 35) provides working definitions for 'the moral domain' and 'the conventional domain.' He describes conventions as relative to the societal context: conventions are rules that vary from one social system to another or when general usage or consensus differs, and they are justified by referring to convention, habit, or behavioral uniformities. For example, a conventional rule has to be followed when and because everybody does it. Turiel (1983: 39) further describes moral rules as universal and justified by referring to concepts of harm, justice and rights. As a consequence, moral rules cannot vary as long as the moral properties of the situation are the same.

Turiel and followers have since employed a specific method (the moral/conventional task) to determine if individuals indeed distinguish conventional from moral rules on the basis of their variability and justification. The dimension of justification is assessed by asking subjects why a specific transgression is wrong, while the dimension of variability is assessed by asking if the act would also be wrong in a different social system, or when general usage differs. Either of these criteria can determine that the transgression is nonrelatively wrong. If a transgression is claimed to be wrong because of consensus, but is claimed to be wrong even when varying a range of societal factors, we cannot decide it is relative - it might be universally wrong. If a transgression is deemed wrong because it causes harm but it is deemed not wrong in a different society B, it might be the case that following the rule in society B would have morally reprehensible consequences and that the rule is in fact based on universal principles of, for example, justice. A rule can only be relatively right or wrong if it's wrongness varies from one society to another and if the rule is justified by referring to local moral views, not by referring to universal moral principles. Hence, under this paradigm, it will be much easier to determine that participants perceive a rule to be non-relative than to determine that participants perceive a rule to be relative.

Consonant with the aforementioned asymmetry in the affordances of the Turiel paradigm, an impressive corpus of empirical investigations employing this conceptual framework supports the conclusion that people are moral non-relativists (e.g., Wainryb et al. 2004; 
Turiel et al. 1987). Indeed, studies find that transgressions that are intuitively judged to be in the moral domain are consistently categorized as generalizably wrong and as wrong due to issues of harm, justice, and rights (e.g., Nucci and Turiel 1993). Despite this voluminous evidence, however, we argue that the methods used in these studies will fail to detect moral relativism when it occurs.

Like Kohlberg, Turiel (1983) premises his approach on a narrow conception of 'morality' and 'conventionality,' drawing on a selection of philosophical theories that support universal accounts of morality (e.g., Searle 1969). Morality is defined as "analytically independent of systems of social organization that coordinate interactions," (Turiel 1983: 39). Moral right and wrong are determined by, and justified by, universal values of justice, rights, and 'do no harm.' As a consequence, what is morally wrong is morally wrong everywhere and its wrongness is justified by these universal values - wrongness is not determined by consensus. This is not a description, as moral systems do vary - it is a definition about the proper moral domain. In this conception, by definition, relativistic rules cannot be moral rules. For example, socio-functional accounts of morality as a device to regulate cooperation (e.g. Wong 2006) are excluded from the scope of research.

In the moral/conventional task, participants are confronted with transgressions that have been selected and categorized by the researchers. In early studies (e.g. Nucci and Turiel 1978; Turiel et al. 1987: 172-174; Nucci and Nucci 1982), researchers or independent jurors classified the transgressions based on the prior definitions of 'moral' and 'conventional.' Some later studies (e.g. Nichols 2004; Nucci and Turiel 1993) adapt previously used scenarios. This opens the possibility that participants had to rate a biased sample of transgressions. There might be transgressions that many of us would intuitively classify as 'moral' but that are not generalizable or not dependent on issues of harm, justice or rights according to the researchers. Such transgressions would not have been included in these studies because they could not have been classified as either 'moral' or 'conventional' due to their 'atypical' combination of characteristics. Hence, the finding that participants rated all 'moral' transgressions as generalizable means nothing more than that the participants agreed with the researchers regarding the generalizability of the selected transgressions. In addition, participants have typically been asked to rate a small number of transgressions. This opens the possibility that their answers were specific to the transgression considered and not to morality per se (Wright et al. 2008). Studies that included a wider range of scenarios and did not have inclusion or characterization criteria based on Turiel's (1983) classification did not find this clear-cut conceptual distinction (e.g. Huebner et al. 2010; Nichols 2004; Kelly et al. 2007). Finally, there are cultural differences in how people classify transgressions. When participants belong to the same cultural group as do the researchers, we can expect that their response patterns will reflect the same intuitions as those of the researchers. Clear cultural differences have been found in the response patterns in regard to putative moral or conventional transgressions (e.g., Miller et al. 1990). Clearly, most studies do not ask participants whether they think of the transgression as moral or conventional - the distinction is made by the researchers, and its affirmation by participants is entirely implicit, dependent on their answers to questions intended to tap into the relevant properties. Wright et al. (2008) presented participants with a broad range of issues and asked them to explicitly classify them as moral or 
conventional. They found that, for almost all issues, there was no consensus among participants. Many issues were considered moral by one participant and conventional by another participant; some of these issues would have been classified as moral according to Turiel's (1983) criteria, while other issues would have been classified as conventional. Huebner et al. (2010) employed principal components analysis to explore how participants' judgments regarding a wide variety of putative moral and conventional transgressions assort. While arguing that postulated moral transgressions do cluster together, they also report that postulated conventional transgressions seem to form a continuum from conventional at one end to moralized at the other end. Findings such as these indicate that there are reasons to doubt the a priori rationale given for drawing the moral/conventional distinction where many researchers place it (see also Bauman and Skitka 2009). We suggest that, unless one knows the participants' categorization, there is no reason to categorize particular transgressions one way or another (indeed, there might not even be a strict conceptual distinction at all, but instead a continuum, with moral and conventional as poles).

This has important implications for the empirical question of whether or not people are moral relativists. Testing a limited range of moral issues is only informative if one expects that some individuals will be extreme relativists. Suppose it were the case that people were moderate moral relativists, deeming as 'moral' some transgressions that researchers in the Turiel tradition did not include or would have classified as 'conventional.' If participants are not asked how they classify such transgressions, and if participants are presented with only a small set of transgressions that have been preselected by researchers on the basis of the intuition that (in the researcher's opinion) each is clearly moral or conventional, then even copious research will not reveal people's relativist leanings.

\section{Ethical Ideologies}

A more open-minded body of research relevant to the present discussion is that employing the Ethics Position Questionnaire (EPQ) developed by Forsyth (1980). Forsyth proposes that people differ in their personal 'ethical ideologies': people differ in the degree they are relativists and idealists, two orthogonal continua ranging from low to high. Forsyth describes highly relativistic individuals as those that "feel that moral actions depend upon the nature of the situation and the individuals involved, and when judging others they weigh the circumstances more than the ethical principle that was violated," (Forsyth 1992). At first glance, this definition might seem to differ substantially from our previous definition of relativism. Nonetheless, consider the components of the EPQ designed to categorize people along this dimension. Participants employ a 9-point Likert scale to indicate how much they agree with each of ten items. In Table 1, we reproduce these ten items, noting in the right column the extent to which each item bears on relativism as we have defined it. Items differ in the extent to which they tap whether people think of moral principles as variable, and whether moral disagreements can be resolved. 
Table 1: Items 11-20 of the Ethics Position Questionnaire (left) and how they relate to our proposed definition of moral relativism (right), from Forsyth 1980.

\begin{tabular}{|c|c|c|}
\hline & Item & Morality is \\
\hline 11 & $\begin{array}{l}\text { There are no ethical principles that are so important that } \\
\text { they should be a part of any code of ethics. }\end{array}$ & $\begin{array}{l}\text { Variable, relative to a } \\
\text { code of ethics }\end{array}$ \\
\hline 12 & $\begin{array}{l}\text { What is ethical varies from one situation and society to } \\
\text { another. }\end{array}$ & $\begin{array}{l}\text { Variable, relative to } \\
\text { situation and society }\end{array}$ \\
\hline 13 & $\begin{array}{l}\text { Moral standards should be seen as being individualistic; } \\
\text { what one person considers to be moral may be judged to be } \\
\text { immoral by another person. }\end{array}$ & $\begin{array}{l}\text { Variable, relative to } \\
\text { individual }\end{array}$ \\
\hline 14 & ypes of moralities cannot be compared as to & $\begin{array}{l}\text { Variable } \\
\text { and irresolvable }\end{array}$ \\
\hline 15 & $\begin{array}{l}\text { S of what is ethical for everyone can never be } \\
\text { since what is moral or immoral is up to the } \\
\text { 1. }\end{array}$ & $\begin{array}{l}\text { Relative to individual, } \\
\text { and irresolvable }\end{array}$ \\
\hline 16 & $\begin{array}{l}\text { Moral standards are simply personal rules which indicate } \\
\text { how a person should behave, and are not to be applied in } \\
\text { making judgments of others. }\end{array}$ & Relativ \\
\hline 17 & $\begin{array}{l}\text { Ethical considerations in interpersonal relations are so } \\
\text { complex that individuals should be allowed to formulate } \\
\text { their own individual codes. }\end{array}$ & Relative to ir \\
\hline 18 & $\begin{array}{l}\text { Rigidly codifying an ethical position that prevents certain } \\
\text { types of actions could stand in the way of better human } \\
\text { relations and adjustment. }\end{array}$ & Variable \\
\hline 19 & $\begin{array}{l}\text { No rule concerning lying can be formulated; whether a lie } \\
\text { is permissible or not permissible totally depends on the } \\
\text { situation. }\end{array}$ & $\begin{array}{l}\text { Variable, relative to } \\
\text { situation }\end{array}$ \\
\hline 20 & $\begin{array}{l}\text { Whether a lie is judged to be moral or immoral depends } \\
\text { upon the circumstances surrounding the action. }\end{array}$ & $\begin{array}{l}\text { Variable, } \\
\text { situation }\end{array}$ \\
\hline
\end{tabular}

Most items combine at least two of the three criteria of individual relativism. When an individual scores high on all of these criteria, we can conclude that the participant explicitly endorses moral relativism as here defined. The items are biased towards extreme moral relativism: moderate moral relativists would agree that some moral standards are individualistic (item 11) or personal rules (item 16), but they would not necessarily agree with the more general wording that is used. Moreover, it is not clear if normative relativism is assessed. 'Relativist' answers are also concomitant with other interpretations, such as meta-ethical relativism (moral statements are relatively true or false) (see also Goodwin and Darley 2010). On the other hand, Forsyth (1992) explicitly avoids an a priori commitment to an objectivistic moral philosophy. All things considered, this is a useful starting point if we want to know about the possibility of lay people being folk moral relativists.

Studies that make use of the EPQ frequently inform us about variation in moral views, as suggested by Flanagan (1991). Researchers often report that, among adults, age is negatively correlated with relativism (e.g., Chen and Liu 2009; Dubinsky et al. 2005; 
Hartikainen and Torstila 2004; Fernando et al. 2008; Vitell and Paolillo 2003). In most studies, religiosity is negatively correlated with relativism (Chen \& Liu. 2009; Barnett et al. 1996; Vitell and Paolillo 2003 but see Fernando et al 2008). Relativism also differs significantly between nations (Forsyth et al. 2008; Alas et al. 2010), with the East generally being more relativistic than the West (Forsyth et al. 2008). We see here that a very general but less biased conception of relativism yields a more nuanced view on folk moral relativism. We suggest that more elaborate scales could differentiate between normative and meta-ethical relativism, between cultural and individual relativism, and between extreme and moderate relativism.

\section{Moral heuristics}

Experimental philosophers have recently begun to examine individuals' implicit moral heuristics by presenting them with scenarios and varying the relevant conditions therein. However, these studies mostly tap into meta-ethical commitments: participants are asked to assess the truth value of moral statements (Sarkissian et al. ${ }^{3}$; Goodwin and Darley 2008, 2010). While these studies offer preliminary indications that some individuals could be meta-ethical relativists, it would be useful to explicitly try to tap into normative implicit heuristics.

A critique that might be raised is that researchers mostly study moral psychology by analyzing subjects' explicit verbal reports of their reasoning while many moral psychologists now hold that moral behavior and moral judgment do not correlate with explicit reasoning (e.g., Haidt 2001; interestingly, Piaget [1932] was already aware of this difficulty). On the other hand, explicit verbal reasoning is used to convince others about one's moral judgments and to influence others' moral behavior (also Haidt 2001). This suggests that it is appropriate to approach the issue of folk morality from different angles: moral behavior, implicit moral judgments, and explicit moral reasoning.

\subsubsection{Development and transparency}

Many developmental studies are premised on the assumption that there is a moral/conventional distinction. These studies suggest that young children (ages 4-7) are non-relativists about morality (e.g., Nichols \& Folds-Bennett 2003; Wainryb et al. 2004). However, some of the previously mentioned caveats are important, most notably that only a small number of typically moral items were tested (hitting, kicking, helping, and breaking another child's toys). This raises the issue that a distinction should be made between extreme and moderate relativism. This distinction is even more important in light of Gabennesch's critique on the development of the moral/conventional distinction. Gabennesch suggests that certain issues might be relativized more easily than others. He reviews previous studies and notes that both moral and conventional transgressions are non-relativistically wrong for young children, while fewer transgressions are relativistically wrong for older children. $\mathrm{He}$ also notes that some conventional

\footnotetext{
${ }^{3}$ Hagop Sarkissian, John Park, David Tien, Jennifer Cole Wright and Joshua Knobe (2010). Folk Moral Relativism. Unpublished manuscript, Baruch College, CUNY.
} 
transgressions are more likely than others to continue to be reified at a later age. This, he argues, is caused by their lack of transparency, the extent to which their human origins are visible for the subject. A range of factors influence a rule's transparency. For example, a rule with which the child is familiar will be more transparent than a new one; a rule that applies only to certain groups or only in certain contexts will be more transparent; and so on. In accordance with this, non-relativism was found to not be exclusive to moral issues (Nichols \& Folds-Bennet 2003; Wainryb 2004). Given the previously stated critique (Section 4.1.1) that it should be up to the participant to explicitly classify rules as 'moral' or 'conventional,' there are not sufficient grounds to conclude that only conventional rules can become relative, while moral rules cannot. Kelly et al. (2007) provide findings consonant with the suggestion that moral rules can be thought of as relative. They find that participants are indeed more likely to say that more historically and locally variable moral rules against slavery or cannibalism are ok or not depending on time and place. However, as Kelly et al. did not ask participants to justify their responses, we cannot know for certain how their findings, including order effects, articulate with folk moral relativism. Also, Nichols (2004) found in one study that moral non-objectivism was positively correlated with years spent in college. Moral nonobjectivism being a function of education is consonant with the transparency hypothesis; nonetheless, more research is needed to establish a potential causal link between nonobjectivism, relativism, and education. Moreover, this finding did not replicate in additional studies (id.). In short, preliminary data suggest that factors that have to do with the rule in question can interact with age or education to make a rule relative, independent of the rule being moral or conventional. While other factors undoubtedly matter in reifying rules (Schweder 1990), Gabennesch's critique is a promising one.

\subsection{Confidence}

Can empirical studies inform the philosophical discussion about moral confidence? More specifically, does moral relativism lead to a weakened adherence to moral principles? Research using Forsyth's EPQ sheds light on the question of whether moral confidence is undergirded by moral non-relativism. More relativistic adult U.S. consumers are less likely to find a range of consumer practices wrong (Vitell \& Paolillo 2003). Practices examined concerned illegal behavior such as changing price tags as a consumer on consumer products, lying about a child's age in order to get a lower price, not telling the truth when negotiating about the price of a car, and illegally copying computer software. Among marketing managers, those who score high on relativism have been found to think that ethics is less important for a firm's long term plans (Vitell et al. 2003). Chinese managers are reportedly more favorable towards bribery and kickbacks if they score higher on relativism (Tian 2008). In another study, relativists are shown to be more accepting of violating property rights (Winter et al. 2004). Business undergraduates at a U.S. university who score higher on relativism score lower on corporate social responsibility, the extent to which they take the wider social impact of their business into account instead of just caring about profits and stockholders (Kolodinsky et al. 2010). Nichols (2004) categorized adult participants as moral non-objectivists if they said that there was no fact of the matter regarding a moral disagreement; otherwise, they were classified as moral objectivists. He made use of the moral/conventional task and found 
that, in all four studies, non-objectivists found 'moral' transgressions less serious (but equally non-permissible) compared to objectivists, suggesting again a negative relationship between relativism and confidence.

Being motivated to act in accordance with moral principles is another major aspect of moral confidence. As for behavior, Forsyth (1980) and Forsyth and Berger (1982) did not find a relationship between ethical position and cheating behavior on a test. On the other hand, Indonesian consumers scoring high on relativism report being more likely to engage in questionable but legal activities, and being more likely to initiate an illegal activity from which they would benefit ( $\mathrm{Lu}$ and $\mathrm{Lu} 2010$ ).

In all of the studies discussed above, it is possible that moral confidence decreases relativism as well as the other way around. Fernando et al. (2008) find that Australian relativist managers score lower on the 'corporate ethical values scale,' which measures the employee's perceived ethical values in his company, and the authors hypothesize that perceived corporate ethical values have a causal influence on relativism scores. Also, these studies do not make a distinction between different kinds of moral relativism. Here it would be particularly interesting to know if the correlation holds for all moral issues or only for a specific subset, and to investigate what happens when people come to take new values into account, as described by Wong (2006),.

\subsection{Tolerance and respect}

We mentioned philosophers who argue that tolerance - not interfering with behavior that one judges to be morally wrong - is psychologically unstable. The purported reason is that a moral judgment involves the desire to regulate others' behavior. There are different gradations of intervention, and openly judging an act may in itself partially inhibit others from performing the given act. Also, even in the case where judgments are kept private, studies suggest that people prefer to distance themselves from others who hold diverging moral beliefs. Haidt et al. (2003) found that participants preferred roommates who held similar political and moral views. They were much more willing to have more moral variation in a classroom seminar, and slightly less at the university as a whole. Other kinds of diversity (e.g., demographic) were much more readily accepted in roommates. This was partly replicated by Wright et al. (2008), whose study we discussed in Section 4.1.1. Participants were less accepting of someone as a potential roommate who differed in moral issues, than of encountering a morally disagreeing person in a seminar or at university as a whole. Participants were also less accepting of encountering someone who disagreed on moral issues than when encountering someone who differed on non-moral issues. They also found that participants would sit farther away from, and more turned away from, a discussion partner who disagreed on a moral issue than a discussion partner who disagreed on a conventional issue. Other subtle changes in behavior occur: participants in an experimental setting gave fewer raffle tickets to a student whom they thought disagreed with them on moral attitudes than they gave to a student who was said to disagree on non-moral attitudes (Wright et al. 2008). This indicates that, at the interpersonal level, the requirement of tolerance may run counter to subtle discriminatory 
mechanisms, such as shunning, that are not easily regulated because of their intimate nature.

This suggests that tolerance is less of a problem between groups that do not intimately interact in the first place. Nonetheless, Lester \& Roberts (2009) noticed that even when participants claimed to tolerate behavior that was symbolic of a worldview they did not agree with, people were less willing to defend the rights of groups with which they did not agree. However, after taking a course on the seven major world religions, students claimed to be more willing to defend the rights of suppressed groups and to allow individuals from all other worldviews to execute their rights. This effect was slight, but significant. It is hard to know whether participants' self-reports reflect their actual behavior, but explicitly formulated judgments might have a general effect on one's own and others' behavior (see also Haidt 2001).

The possibility of tolerance might depend on the principles in question, and the relativism or age of actors. In observations of naturally-occurring behavior among 7 to 14 year old children in Chicago, Nucci \& Nucci (1982) find that moral transgressions elicited more retaliatory actions than did conventional transgressions; however, conventional transgressions elicited more ridicule than did moral transgressions, and there were no differences in threats and commands to stop the act between the two kinds of transgressions. There were no main age effects for retaliation, threat, ridicule or command. Smetana (1981) asked 2 to 9 year old children if perpetrators deserved punishment and how much (none, a little or a lot). She found that moral transgressions were deemed more punishable than conventional transgressions. Hollos et al. (1986) tested 8-18 year old Nigerians and found that these participants wanted an authority figure to react to moral transgression by flogging the transgressor. However, in line with the previously discussed age differences, 8-11 year old subjects thought that conventional transgressions should be punished by flogging, while 15-18 year old subjects gave this response significantly less. These findings suggest that both moral and conventional transgressions do elicit interference from children and adolescents, be it in the form of punishment, retaliation, ridicule, threats, or commands. However, since it is likely that moral transgressions are less tolerated than conventional transgressions, it is also likely that, mediated by age, relativized moral judgments will be more tolerated than universal or objective moral judgments.

Similar age differences are evident in the realm of respect. Here we have to ask how people judge others with whom they morally disagree, as opposed to judging their moral opinions. In Section 4.1.1, we discussed the study of Wainryb et al (2004), conducted among 5 to 9 years old children. The moral issues used were breaking other children's toys and kicking other children. The children used positive descriptors to describe the characters who expressed divergent beliefs bearing on taste, ambiguous facts, and facts, but they described as bad characters who expressed divergent moral beliefs. Regardless of the realm of disagreement, 7-9 year olds described disagreeing characters as nice or normal more often than did 5 year olds. Enright and Lapsley (1981) presented a short vignette to adults, students from grades 3 to 12, and college students, and asked for their judgment about a moral dilemma. They then confronted participants with an audio-taped 
peer stating the opposite judgment. Participants could then choose what they thought about the other person. Possible items were "The other does not seem to be a predominantly good person but there is some good in everyone" (level 1), "the other is probably as good a person as anyone else" (level 2) and "I cannot tell what kind of a person the other is until I know much more about the other's beliefs" (level 3). The authors found that college students were most likely to agree with level 3-like items, denoting that one can judge others, but not based on only this one moral belief; adults (older than college students but matched on amount of education) scored slightly lower than college students. This indicates that character judgments are initially linked to moral belief judgments, and that respect increases with age or education, regardless of the realm of disagreement. This is also analogous to the finding that education is positively related to relativism (see Section 4.1.2). Again, we conclude that factors that have to do with the rule in question could make diversity more or less difficult to respect, highlighting the need for moderate accounts of tolerance and respect.

\section{Summary and conclusions}

Naturalist philosophers welcome empirical evidence to constrain or support theories of normative relativism. An important critique against all versions of normative relativism holds that individuals think of morality as non-relative, therefore it is not feasible to impose normative relativism as a requirement. At first sight, results from moral psychology inspired by Kohlberg and findings from domain theory, indeed suggest that morality is inherently non-relative: children and adults are non-relativists about moral rules, and they only relativize rules that are not in the moral domain. However, a deeper look suggests that skepticism is in order, as much of moral psychology defines morality as non-relative, either implicitly or explicitly. Subsequently, no measures are taken to independently decide whether or not participants' moral reasoning is at work. As such, no relative rule will ever be described under the headings of moral psychology. While it might well be the case that people are moral non-relativists, the methods employed in most of this research are biased against finding moral relativist leanings.

Other traditions, for example research making use of the Ethics Position Questionnaire, do find diversity in moral views. Moral relativism is less abundant in the West and among religious people, and it declines with age among adults. Promising possibilities of folk moral relativism can also be found in moral development research and studies that are critical of mainstream interpretations of the moral/conventional distinction. Older children treat a wider range of rules as relative than do younger children. Assuming that some of these rules might be categorized as moral by the children themselves, children might become more relativistic in the course of moral development. The relativity of moral rules might also depend on the specific properties of the rule, most notably the degree to which their human origins are transparent. In all of this, we have to keep in mind that it is unlikely that people are extreme moral relativists. Therefore, it is important to test participants on a range of issues. Here, the lack of an encompassing theory of folk moral relativism makes it difficult to predict what moral rules are likely to be relativized and who will be what kind of moral relativist. 
The second worry is that we need the idea that morality is objective in order to have confidence in our moral values. Some results are in accordance with moral relativism being negatively correlated with moral confidence as measured by perceived seriousness of moral transgressions and judging moral behavior. However, researchers have yet to explore the relationship between moral relativism and actual behavior. Moreover, these studies do not inform us much regarding the direction of causality, which could go either way - as such, philosophers' intuitions that relativism correlates with decreased confidence might reflect an existing correlation, but with the causal arrows going from confidence to relativism instead of the other way around. More research on this topic is clearly necessary.

A third constraint is linked to the requirement of tolerance: judging an action to be wrong purportedly implies that we are motivated to stop the action. The paradoxical nature of tolerance led philosophers to develop notions of respect and ambivalence. Studies do find a link between moral (and conventional) disagreement and interference; this speaks against tolerance as a feasible strategy towards much of moral diversity. However, findings to date also suggest that distance, operationalized as amount of intimate interaction, can be a mediating factor, suggesting the need to distinguish between cultural and individual moral diversity. Moreover, we find the same moderating factors for tolerance and respect as for moral relativism - age and education seem to impact one's capacity to tolerate and respect certain other ways of life. The possibility remains that moderate tolerance and respect are psychologically feasible.

We therefore arrive at the following circumspect conclusions. Major traditions in the empirical literature seem to support the view that morality is intuitively thought of as objective. However, a deeper reading indicates that caution is in order here. It is indeed unlikely that people are extreme moral relativists, meaning that no moral rules are thought of as objective or universal. However, this should not be taken as implying that moral rules are intrinsically non-relative: there are both individual differences and properties of the rules themselves that influence whether or not a rule is thought of as relative. Results indicate that, in the course of moral development, individuals might become more relativist, tolerant, and respectful. More transparent rules might be more likely to become relativized. Moreover, results are consistent with tolerance and respect being mediated by distance to others. In sum, it is likely that many people are, or can be, moderate moral relativists.

All in all, this is a relatively underexplored field, both in empirical work and in philosophical theories. We argue that empiricists can learn from philosophers when investigating folk moral relativism. Future research would provide a clearer portrait of the nature and extent of folk moral relativism were investigators to adopt some rules of thumb. First, participants should always be asked to categorize events as moral or nonmoral instead of leaving this categorization solely to the researchers. Second, a distinction should be made between the extremes of individual and cultural relativism. Preliminary evidence indicates that adults are more likely to tolerate cultural than individual diversity. Since this is an important philosophical and social distinction, it is one of the mediating factors that deserve empirical attention. Third, we would urge 
researchers to investigate the development of relativism for 'transparent' moral issues, such as gender discrimination, hierarchy, inequality, or modes of punishment. One should take into account that relativism most likely does not mean extreme relativism. Finally, investigators should probe implicit heuristics as well as explicit reasoning and behavior. Behavior is of primary importance for discussions surrounding confidence and tolerance. Lastly, studies in which participants are asked to evaluate the person as well as the behavior are particularly informative for the notion of respect.

In contrast to the diversity of philosophical perspectives being developed on these issues, most empirical researchers have been, and continue to be, deeply influenced by modern Western moral philosophies; as such they conceptualize morality as objective. Due to its influence on methodological design, this perspective then biases empirical findings accordingly. Similarly, most empirical research that addresses relativism, objectivity, or universalism does so in broad categorical fashion, ignoring philosophers' distinctions between different kinds of moral relativism, and this despite the fact that at least some of the empirical findings to date indicate that such distinctions should be taken seriously. It is time that, on the one hand, more philosophers recognize the empirical nature of much of the discussion surrounding relativism, and, on the other hand, moral psychologists question their conceptual assumptions. Awareness of both existing findings and lacunae therein should invite philosophers to become more familiar with the empirical literature at hand; it should also invite more empiricists to directly address the question of folk moral relativism without presupposing it.

\section{Acknowledgments}

K.Q. is grateful for the financial support of the Fonds Wetenschappelijk OnderzoekVlaanderen. Without implying that they would agree with our perspectives, we thank UCLA's XBA group, and Stephen Stich, whose ideas helped shape our thoughts on these matters.

\section{References}

Alas R, Gao JH, Carneiro J (2010) Connections between ethics and cultural dimensions. Inzinerine Ekonomika-Eng Econ 21 (3):255-262

Barnett T, Bass K, Brown G (1996) Religiosity, ethical ideology, and intentions to report a peer's wrongdoing. J Bus Ethics 15 (11):1161-1174

Bauman CW, Skitka LJ (2009) In the mind of the perceiver: Psychological implications of moral conviction. Psychol learn motiv: adv res theory 50:339-362

Benedict R (1934/2001) Anthropology and the abnormal. In: Moser PK, Carson TL (eds) Moral relativism a reader. Oxford University Press, New York/Oxford, pp 80-79

Beebe JR (2010) Moral relativism in context. Noûs 44 (4):691-724 doi: 10.1111/j.14680068.2010.00763.x

Brandt R (1967/2001) Ethical relativism. In: Moser PK, Carson TL (eds) Moral relativism a reader. Oxford University Press, New York/Oxford pp 25-31

Campbell RL, Christopher JC (1996) Moral development theory: A critique of its kantian presuppositions. Dev Rev 16 (1):1-47 
Chen SY, Liu CC (2009) Relationships between personal religious orientation and ethical ideologies. Soc Behav Personal 37 (3):313-320. doi:10.2224/sbp.2009.37.3.313

Doris J M, Plakias A (2008) How to Argue about Disagreement : Evaluative Diversity and Moral Realism. In: Sinnott-Armstrong W (ed) Moral Psychology Volume 2 The Cognitive Science of Morality: Intuition and Diversity. MIT Press, Cambridge/London, pp 303-332

Dubinsky AJ, Nataraajan R, Huang WY (2005) Consumers' moral philosophies: Identifying the idealist and the relativist. J Bus Research 58 (12):1690-1701. doi:10.1016/j.jbusres.2004.11.002

Enright R, Lapsley D (1981) Judging others who hold opposite beliefs: The development of belief discrepancy reasoning. Child Dev 52 (3):1053-1063. Stable URL: http://www.jstor.org/stable/1129111

Fernando M, Dharmage S, Almeida S (2008) Ethical ideologies of senior australian managers: An empirical study. J Bus Ethics 82 (1):145-155. doi:10.1007/s10551007-9568-0

Flanagan O (1991) Varieties of moral personality. Ethics and psychological realism. University Press, Harvard

Fletcher G (1996) The instability of tolerance. In: Heyd D (ed) Toleration. An elusive virtue. Princeton University Press, Princeton pp 158-172

Forsyth DR (1980) A taxonomy of ethical ideologies. J Person Soc Psychol 39 (1):175184 doi : 10.1037/0022-3514.39.1.175

Forsyth DR (1992) Judging the morality of business practices - the influence of personal moral philosophies. J Bus Ethics 11 (5-6):461-470 doi: 10.1007/BF00870557

Forsyth DR, Berger RE (1982) The effects of ethical ideology on moral behavior. The J Soc Psychol 117 (1):53-56 doi: 10.1080/00224545.1982.9713406

Forsyth DR, O'Boyle EH, McDaniel MA (2008) East meets west: A meta-analytic investigation of cultural variations in idealism and relativism. J Bus Ethics 83 (4):813-833. doi:10.1007/s10551-008-9667-6

Gabennesch H (1990) The perception of social conventionality by children and adults. Child Dev 61 (6):2047-2059 doi: 10.1111/j.1467-8624.1990.tb03586.x

Goodwin GP, Darley JM (2008) The psychology of meta-ethics: Exploring objectivism. Cognition 106(3):1339-1366 doi: 10.1016/j.cognition.2007.06.007

Goodwin GP, Darley JM (2010) The perceived objectivity of ethical beliefs: Psychological findings and implications for public policy. Review of Philosophy and Psychology 1 (2):161-188 doi: 10.1007/s13164-009-0013-4

Haidt J (2001) The emotional dog and its rational tail: A social intuitionist approach to moral judgment. Psychol Rev 108 (4):814-834. doi:10.1037//0033295x.108.4.814

Harman G, Thomson JJ (1996) Moral relativism and moral objectivity. Blackwell, Oxford

Hartikainen O, Torstila S (2004) Job-related ethical judgment in the finance profession. J Appl Finance Spring/Summer: 62-76

Heyd D (ed) (1996) Toleration. An elusive virtue. Princeton University Press, Princeton

Huebner B, Lee JJ, Hauser MD (2010) The moral-conventional distinction in mature moral competence. J Cognition Culture 10 (1-2):1-26 doi:

$10.1163 / 156853710 X 497149$ 
Kelly D, Stich S, Haley KJ, Eng SJ, Fessler DMT (2007) Harm, affect, and the moral/conventional distinction. Mind Lang 22 (2):117-131 doi: 10.1111/j.14680017.2007.00302.x

Kolodinsky RW, Madden TM, Zisk DS, Henkel ET (2010) Attitudes about corporate social responsibility: Business student predictors. J Bus Ethics 91 (2):167-181. doi:10.1007/s10551-009-0075-3

Levy N (2002) Moral relativism a short introduction. Oneworld Publications,

Lu LC, Lu CJ (2010) Moral philosophy, materialism, and consumer ethics: An exploratory study in indonesia. J Bus Ethics 94 (2):193-210. doi:10.1007/s10551009-0256-0

Miller JG, Bersoff DM, Harwood RL (1990) Perceptions of social responsibilities in india and in the united states: Moral imperatives or personal decisions? J Personal Soc Psychol 58 (1):33-47 doi: 10.1037/0022-3514.58.1.33

Nichols S (2004) Sentimental rules. On the natural foundations of moral judgment. University Press, Oxford

Nichols S, Folds-Bennett T (2003) Are children moral objectivists? Children's judgments about moral and response-dependent properties. Cognition 90:B23-B32 doi:10.1016/S0010-0277(03)00160-4

Nucci L, Nucci MS (1982) Children's responses and social conventional transgressions in free-play settings. Child Dev 53 (5):1337-1342 Stable URL: http://www.jstor.org/stable/1129024

Nucci L, Turiel E (1993) God's word, religious rules, and their relation to christian and jewish children's concepts of morality. Child Dev 64(5):1475-1491 Stable URL: http://www.jstor.org/stable/1131547

Nucci LP, Turiel E (1978) Social interactions and development of social concepts in preschool-children. Child Dev 49 (2):400-407 Stable URL: http://www.jstor.org/stable/1128704

Rest JR (1979) Development in judging moral issues. University of Minnesota Press, Minneapolis, Minnesota

Rest JR (1983) Morality. In: Flavell JH, Markman EM (eds) Handbook of child psychology, vol 3: Cognitive development. Wiley, New York, pp 556-629

Rest JR (1988) Why does college promote development in moral judgement? J Moral Education 17 (3):183 - 194 doi: 10.1080/0305724880170303

Ruse M (1986) Evolutionary ethics: A phoenix arisen. Zygon 21:95-112

Searle J (1969) Speech acts: An essay in the philosophy of language. Cambridge University Cambridge, England

Sinnott-Armstrong W (2009) Mixed-up meta-ethics. Philosophical Issues 19 (1):235-256 doi: 10.1111/j.1533-6077.2009.00168.x

Smetana JG (1993) Understanding of social rules. In: Bennett M (ed) The development of social cognition: The child as psychologist. Guilford Press, New York, pp 111141

Shweder RA (1990) In defense of moral realism: Reply to gabennesch. Child Dev 61 (6):2060-2067 Stable URL: http://www.jstor.org/stable/1130859

Smetana JG (2006) Social-cognitive domain theory: Consistencies and variations in children's moral and social judgments. In: Smetana JG, Killen M (eds) Handbook 
of moral development. Lawrence Erlbaum Associates, Mahwah, New

Jersey/London, pp 119 - 153

Sumner WG (1906/2001) Folkways. In: Moser PK, Carson TL (eds) Moral relativism a reader. Oxford University Press, New York/Oxford pp 69-79

Tian Q (2008) Perception of business bribery in china: The impact of moral philosophy. J Bus Ethics 80 (3):437-445. doi:10.1007/s10551-007-9429-x

Turiel E (1983) The development of social knowledge: Morality and convention.

Cambrdige University Press, Cambridge

Turiel E, Killen M, Helwig C (1987) Morality. Its structure, functions and vagaries. In: Kagan J, Lamb S (eds) The emergence of morality in young children. University of Chicago Press, Chicago, pp 155-243

Vitell SJ, Paolillo JGP (2003) Consumer ethics: The role of religiosity. J Bus Ethics 46 (2):151-162

Wainryb C, Shaw LA, Langley M, Cottam K, Lewis R (2004) Children's thinking about diversity of belief in the early school years: Judgments of relativism, tolerance, and disagreeing persons. Child Dev 75 (3):687-703 doi: 10.1111/j.14678624.2004.00701.x

Winter SJ, Stylianou AC, Giacalone RA (2004) Individual differences in the acceptability of unethical information technology practices: The case of machiavellianism and ethical ideology. J Bus Ethics 54 (3):279-301 doi: 10.1007/s 10551-004-1772-6

Wong DB (1984) Moral relativity. University of California Press, Berkeley/Los Angeles/London

Wong DB (2006) Natural moralities. University Press, Oxford

Wright JC, Cullum J, Schwab N (2008) The cognitive and affective dimensions of moral conviction: Implications for attitudinal and behavioral measures of interpersonal tolerance. Personal Soc Psychol Bull 34 (11):1461-1476

doi:10.1177/0146167208322557 